\title{
PREFABRICATED SECONDARY UNITS FOR OVERCOMING THE SHORTAGE OF HOUSES: A CASE STUDY OF NEW ZEALAND
}

\author{
Milad Moradibistouni ${ }^{1 *}$, Brenda Vale $^{2}$ and Nigel Isaacs ${ }^{3}$ \\ ${ }^{1,2}{ }^{2}{ }^{3}{ }^{3}$ Department of Architecture and Design, Victoria University of Wellington, Wellington, New Zealand \\ *Milad.bistouni@vuw.ac.nz
}

\begin{abstract}
This paper focuses on providing affordable houses in the form of prefabricated Accessory Dwelling Units (ADUs) for the changing demographics of New Zealand. The goal is also to use the existing urban infrastructure. Following global trends, the New Zealand population is growing but at the same time household size is falling with an ageing population, leading to a shortage of both numbers of and suitably sized houses to allow people to age in place in their existing communities. There is thus a need for a method of construction that can deliver more houses in a shorter time. Prefabrication is potentially faster, cheaper, and more efficient in comparison with traditional methods. Putting more dwellings in the form of small, prefabricated ADUs on the large plots of existing houses could potentially accommodate more people in urban areas. As a start in testing the feasibility of this idea, this paper discusses data collected from existing off-site manufacturers in New Zealand to give a better understanding of where they are located and what they offer. It then investigates the transportation rules of New Zealand and the rules of the 71 councils of New Zealand related to constructing ADUs, in order to better understand what could be mass produced that would best meet the criteria for ADUs in council areas with the most need. These parameters lead to the design of a series of ADUs that could help overcome the shortage of appropriate houses in New Zealand. The paper ends by presenting and discussing the proposed designs.
\end{abstract}

\section{Introduction}

Since 1948 the population of New Zealand has been growing and this trend is predicted to continue through the second half of this century. In 2017 the population was 4.8 million and there is a $90 \%$ probability of this increasing to 6.0 million by 2043, with $75 \%$ of these New Zealanders living in urban areas (Statistics New Zealand, 2016). This growth has led to a current shortage of 71,000 houses in New Zealand, increasing by 40 houses a day (Miller, 2017). Khajehzadeh and Vale (2017a) show that in recent decades fewer people are living in each house, while at the same time the floor area of new houses has increased. A report from Quotable Value (2011) reveals that based on the decade they were built the average area of new dwellings increased from $131 \mathrm{~m}^{2}$ in 1900 to over $200 \mathrm{~m}^{2}$ in 2010 (Figure 1). In 2012 the average area of new houses in New Zealand was $195 \mathrm{~m}^{2}$ compared to approximately $85 \mathrm{~m}^{2}$ in the UK (Evans, 2012). Moreover, the number of persons in each household has decreased from 3.7 in 1951 to 2.6 in 2013 and is predicted to fall to 2.4 by 2031 (Statistics New Zealand, 2015).

Looking at the age of New Zealanders, those aged 65+ increased by over $100 \%$ from 1951 to 2000 . This population group, which was less than 200,000 in 1951, exceeded 400,000 in 2000 and is predicted to exceed 900,000 by 2031 (Khawaja and Thomson, 2000). Give this same sector of the population also consists of small households of one or two people this increase will exacerbate the current housing shortage.
Figure 1 The average size of a house in New Zealand $\left(\mathrm{m}^{2}\right)$

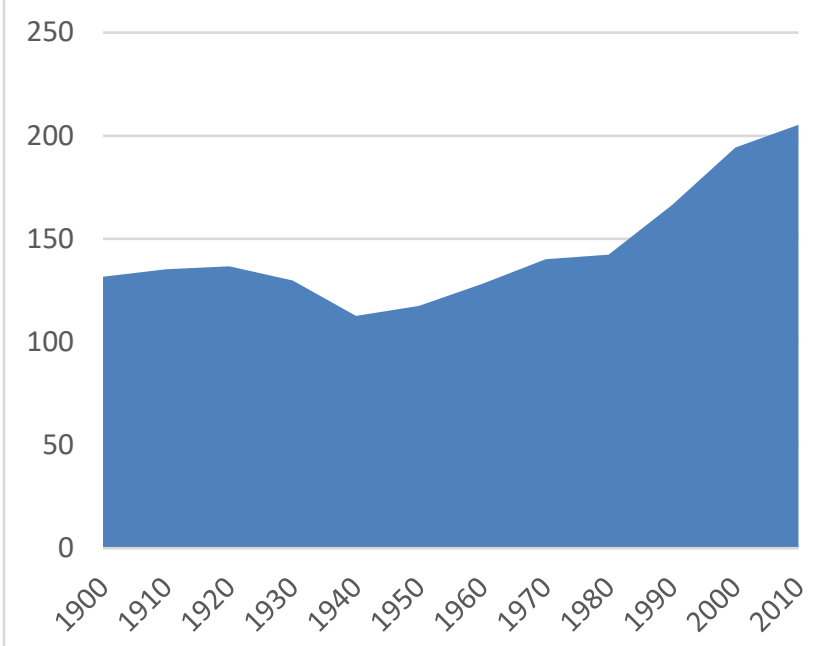

Source: Quotable Value, 2011

What these statistics show is first there is the need to build more houses quickly to meet the needs of a growing population in New Zealand but also there is a need for appropriate, small houses to meet the needs of the ageing population. Housing costs have also increased with the purchase price from the new housing price index (excluding the land) rising by over $38 \%$ from June 2009 to June 2017, (Statistics New Zealand, 2017a). If a means could also be found of providing cheaper houses this would be a help for the many people currently struggling to enter the housing market. As a result, this paper is based on the design of prefabricated Accessory Dwelling Units (ADUs) as 
a response to these needs due to their potential benefits in terms of time and cost. As part of a comprehensive study of this idea, this paper reports on a study of where prefabrication manufacturers are currently located in New Zealand and what they produce, transport limitations, and the council rules related to the design and use of ADUs. The aim is to create the parameters for designing a prefabricated ADU that could meet the current demand for smaller, cheaper houses.

\section{Prefabrication}

Prefabrication is a method of construction where building elements are manufactured far away from the final location and transported to the site to be craned, assembled and attached to the foundation (Moradibistouni et al, 2018a). Compared with traditional methods of construction, prefabrication is up to $57 \%$ faster, creates $40-90 \%$ less waste, involves $30-70 \%$ fewer environmental impacts, and is potentially $15 \%$ cheaper (Gorgolewski, 2005, pp.125-126; Britto, 2008, p.14). Reduced environmental impacts come from being approximately 50\% more efficient in the use of energy, water and raw materials while reducing $\mathrm{CO}_{2}$ emissions by 35\% (Gorgolewski, 2005, pp.125-126; Britto, 2008, p.14; Bell, 2012, p.16; Phillipson, 2001, p.3). Prefabrication can be classified into the following categories (Bell, 2012):

- Component: simple pre-cut elements and more complicated sub-assemblies such as complete windows;

- Panel: two-dimensional elements made of components joined in the factory such as a partition or wall panel;

- Volume: three-dimensional factory-made modules from combining sub-assemblies, such as factorymade panels;

- Hybrid: a combination of volumes, usually for services areas, and panels assembled on site;

- Complete building: whole factory-made building transported to the site as one unit (Figure 2).

Figure 2 Different types of prefabrication

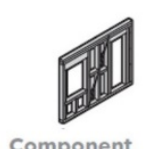

Component

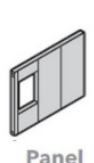

Panel

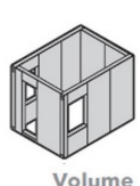

Volume
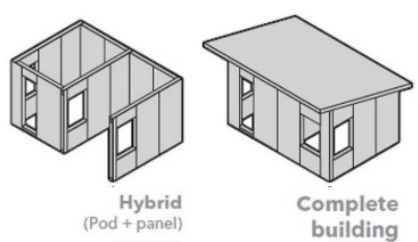

higher quality, less time on site, and more complex transport considerations.

\section{Accessory Dwelling Unit (ADU)}

An ADU is a self-contained secondary unit, independent from the primary dwelling on the site that provides independent living facilities for its occupants. ADUs have the potential to add to the housing stock using existing infrastructure and can increase urban residential density with the least constructionrelated changes to the neighbourhood environment. The residential density of cities in New Zealand is approximately 2,200 persons per square kilometre $\left(\mathrm{ppk}^{2}\right)$ which is considerably lower than in other countries. For example London is 5,100 $\mathrm{ppk}^{2}$ and Mumbai is 35,000 $\mathrm{ppk}^{2}$ (Evans, 2012). This suggests there could be space for inserting ADUs into the existing urban fabric.

ADUs come in the four forms of partitioned, converted, attached, and detached (Saville-Smith et al, 2017).

- Partitioned: these use internal partitions to divide an existing dwelling into two or more units with no change in the envelope (Figure 3 ).

Figure 3 Partitioned ADU

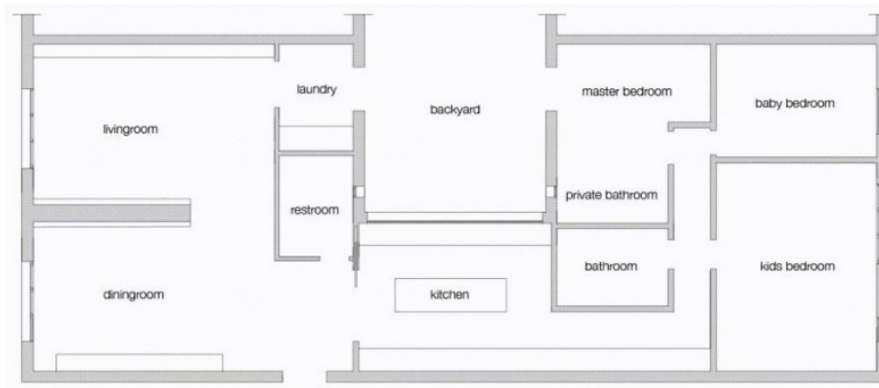

Before conversion

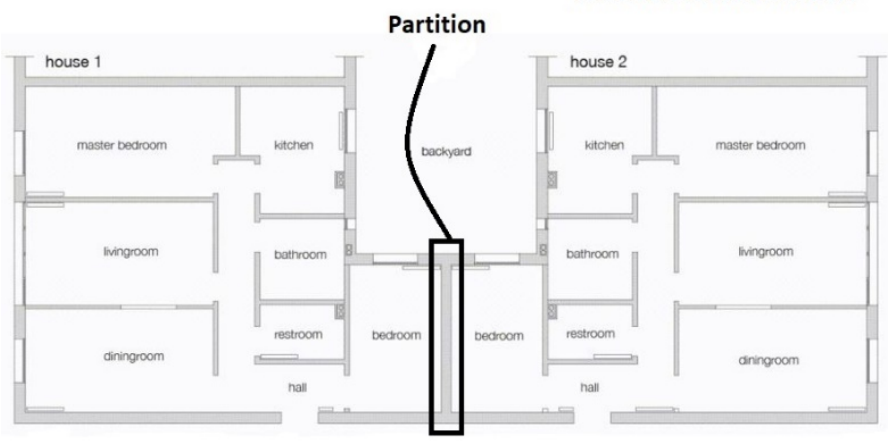

After conversion
Each of these prefabrication systems has benefits and disadvantages, which make each suitable for different situations and needs. Components and panels are very flexible and easy to transport, while volumes and completed buildings are the opposite but need the least on-site works and there is also less chance of potential defects in the final product than with other types. In between, the hybrid system combines the higher quality of volumes with the flexibility of panels. Generally speaking, a higher degree of prefabrication means

Source: Mimoso, 2019

- Converted: these are existing spaces such as a basement, attic or garage converted to a separate dwelling by adding cooking facilities, a bathroom, and a living and sleeping space (Figure 4). 
Figure 4 Converted ADU
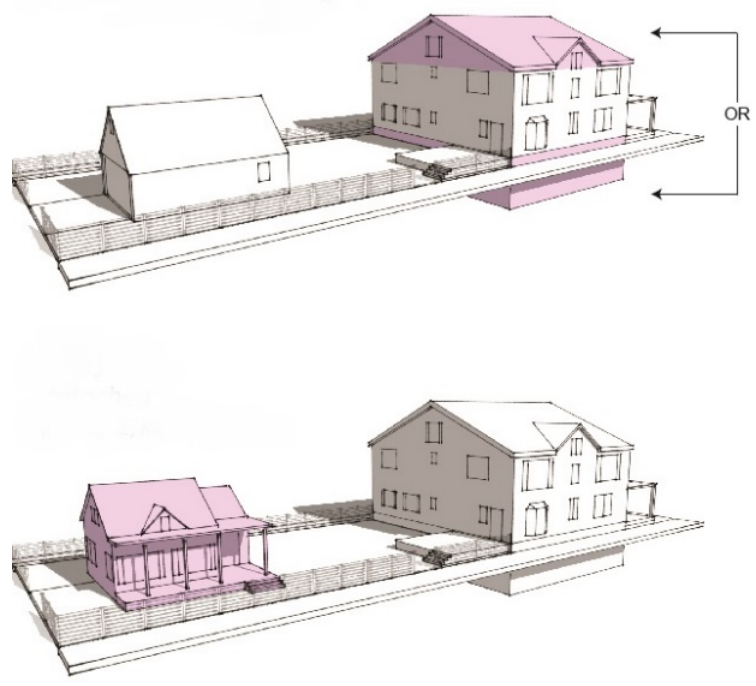

Source: Boulder, 2019

- Attached: these are new independent buildings that are physically attached to the primary unit as an extension (Figure 5).

Figure 5 Attached ADU

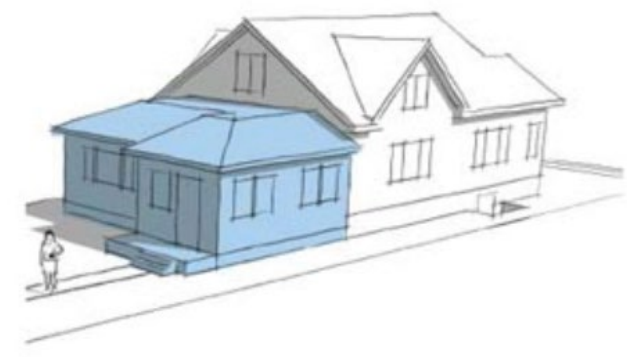

Source: Boulder, 2019

- Detached: these are new independent buildings located on the same lot but not connected to the primary unit (Figure 6).

Figure 6 Detached ADU

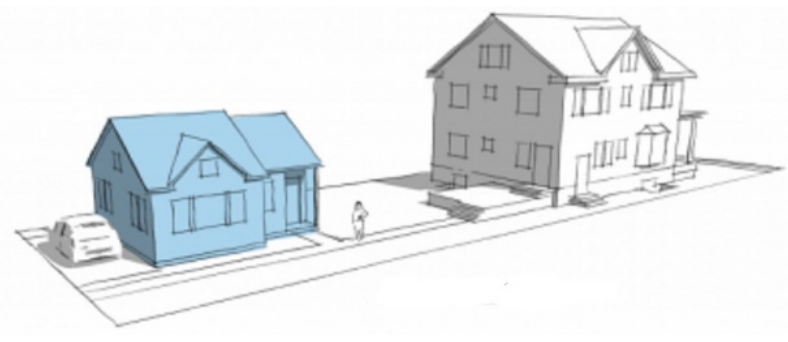

Source: Boulder, 2019
Other ways of providing more houses and increasing the residential density of cities, such as inserting more high rise buildings, could be a slower and potentially more costly process than using ADUs, although both approaches might be necessary. Using ADUs would also allow older people to stay in their neighbourhood and age in the place. A recent study has suggested:

"From partitioning under-utilized dwellings alone, we estimate that around $12 \%$ of New Zealand's housing stock could be partitioned and deliver over 360,000 dwellings. That is 180,000 additional dwellings without impinging on greenfield sites or unutilized vacant residential land" (SavilleSmith et al, 2017).

\section{Methodology}

This paper is a small part of a larger study of prefabricated dwellings for New Zealand and looks at three aspects of creating ADUs as a means of establishing design parameters. The first is the approach to prefabricating the ADU at the factory, the second is how best to transport it to the final location for assembly, and the third is the differing local rules for ADUs in New Zealand. The paper ends by linking the results of this investigation together with a design that considers appropriate values for all factors.

For the first step, a web-based search was undertaken to find out where manufacturers are located and what types of prefabrication they offer. The full process of how this was done is set out in Moradibistouni et al (2018a). Having an idea about the location of factories and the type of prefabrication each manufacturer offers, the New Zealand road rules were investigated to see how big (length, width and height) loads can be before they need to apply for oversize load permission. The assumption behind this is that transportation should be as easy as possible if numbers of prefabricated ADUs are to be produced.

The third step was studying the rules related to the use of ADUs in New Zealand to see how much variation there was in these as set by the 71 local councils based on the report of SavilleSmith et al (2017). The extensive variety revealed led to over 180 subcategories. While all of these were investigated in the larger study, only the rules related to the three main sub-groups of maximum site coverage, maximum gross plan area (GPA), and minimum net site required, are presented here because of their influence on design.

\section{Status of prefabrication manufacturers throughout New Zealand}

The numerical outputs of the survey of manufacturers of prefabrication in New Zealand can be analyzed based on the types of service each manufacturer offers and the location of each (Figure 7).

The services provided by the 51 manufacturers investigated, have been classified into the eight prefabricated categories of 
component; panel; volume (often referred to by the manufacturers as module); container; completed building; kitchen; bathroom; and other. The results show that the majority (22 manufacturers) offer component based prefabrication. After components, the second biggest group are panelized system producers (12 manufacturers). There are also four manufacturers of prefabricated bathrooms and another four of complete building systems. Four manufacturers make prefabricated modules (volumes) and three make prefabricated kitchens. Two factories offering converted containers. These are shipping containers modified and converted to modular living units. The "other" category includes one factory offering prefabricated wiring systems. These data show that over $60 \%$ of all manufacturers offer component based and panelized prefabrication, which are systems with a lesser degree of prefabrication.

Regarding the distribution of manufacturers throughout New Zealand, Figure 7 shows of the 16 regional divisions, 9 have at least one prefabrication factory, and just 14 factories are located in the South Island, in two regions. Having 37 prefabrication manufacturers in the North Island in seven regions, fits well with the fact in 2013 approximately $75 \%$ New Zealand households were located in the North Island, with a growth rate of $1.1 \%$ in the year compared with $0.9 \%$ for the South Island (Statistics New Zealand, 2015). Similarly, Statistics New Zealand (2017b) show 77\% of the New Zealand population, which was approximately 4.8 million in 2017 , lived in the North Island with an annual growth rate of $2.2 \%$, while that of the South Island was $1.8 \%$. Statistics New Zealand (2017b) also showed that from 1921 to 2017 the New Zealand median centre of population moved 280 kilometres north, closer to the Auckland region.

"New Zealand's population density at 30 June [2017] was 18 people per square kilometre, compared with 13 in 1991. However, there is considerable variation at the local level, ranging up to 18,000 people per square kilometre in Central Auckland" (Statistic New Zealand, 2017b).

After Auckland, the Wellington and Canterbury regions had the highest population density in 2017 (Statistics New Zealand, 2017b). Between 2006-2013 Auckland also had the fastest population growth rate of $8.5 \%$, becoming $2.6 \%$ in 2017 , the highest in the country, closely followed by Waikato and Northland both with a growth rate of $2.4 \%$ (Statistics New Zealand, 2013; Statistics New Zealand, 2017c).
Figure 7 Manufacturers and type of prefabrication in each region

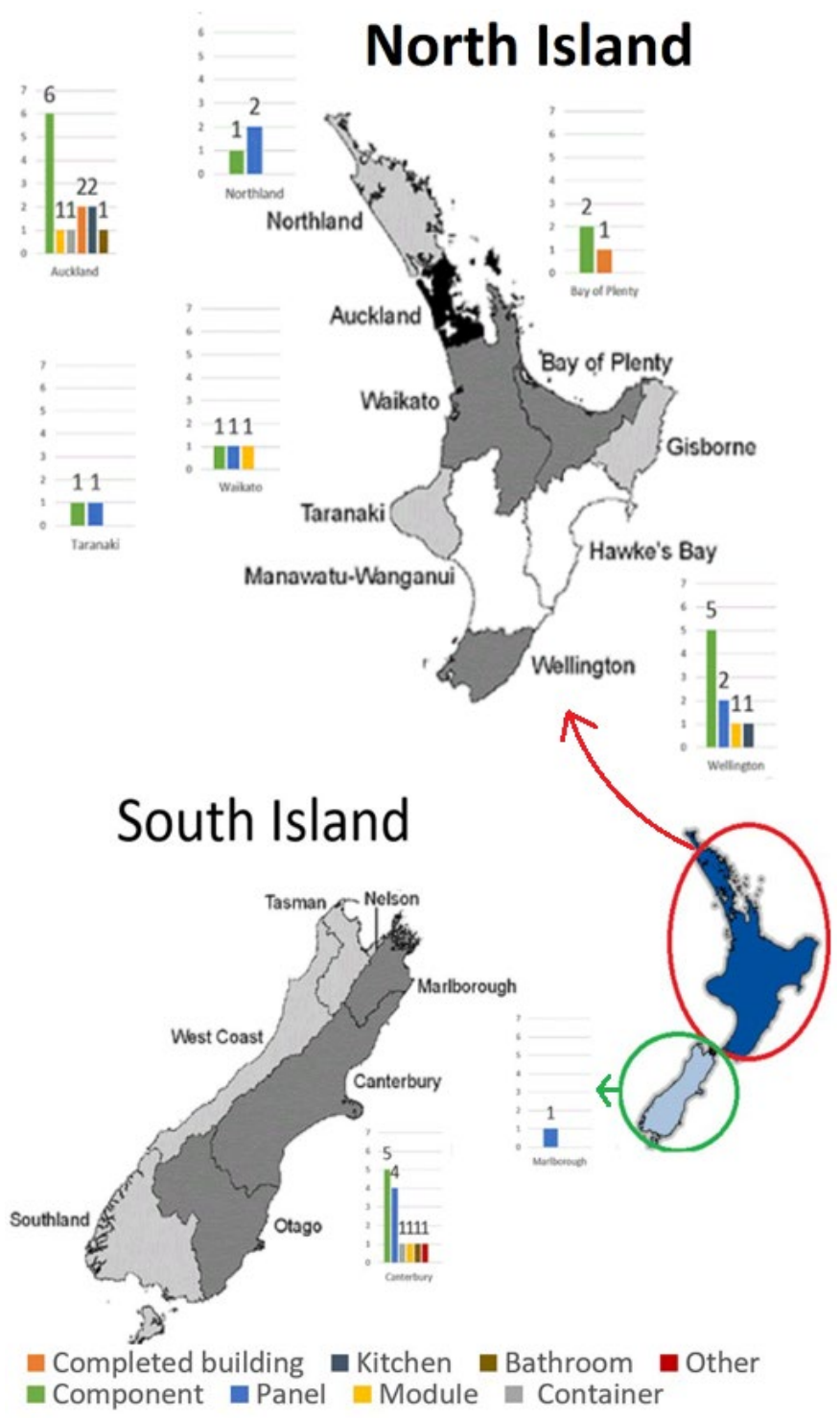

The South Island, with fewer people, is over 150 square kilometres while the area of the more populated North Island is approximately 114 square kilometres. This initially means prefabricated loads need to travel a longer distance in the South Island where the number of manufacturers is also low, but the demand is also probably less. However, it should be noted that in 2017 over $50 \%$ of the total population of the South Island lived in the Canterbury region, which could be the reason 13 manufacturers are located there (Environment Canterbury Regional Council, 2018).

\section{Transport}

Transportation is one of the most important factors negatively affecting any extension of the prefabrication industry, as carrying large prefabricated elements entails considering legal and logistical requirements (Moradibistouni and Gjerde, 2017). An initial step in designing a prefabricated ADU should 
be investigating the maximum size of loads which can be transported without the need for oversized load permission, as the latter will entail additional time and cost. Table 1 shows the maximum allowed loads without oversized load permission in New Zealand, allowing that transit rules may be different in other countries.

Table 1 Allowable loads on New Zealand roads

\begin{tabular}{|c|c|c|c|}
\hline & $\begin{array}{l}\text { Limit } \\
(\mathrm{m})\end{array}$ & Comments & Source \\
\hline Width & $\begin{array}{l}2.5- \\
2.55\end{array}$ & \multirow{2}{*}{$\begin{array}{l}\text { Height } \\
\text { includes } \\
\text { the truck } \\
\text { height }\end{array}$} & $\begin{array}{l}\text { Stockdale,2016; Petterson, } \\
\text { 2016;NZ Transport }\end{array}$ \\
\hline Height & $\begin{array}{l}4.25- \\
4.30\end{array}$ & & Agency, 2017a \\
\hline Length & 20 & & $\begin{array}{l}\text { Stockdale, 2016; Petterson, } \\
\text { 2016; Road transport } \\
\text { forum NZ, } 2018 \text {; Transport } \\
\text { Agency, } 2017 \text { (b); } \\
\text { Transport Agency, } 2017 \\
\text { (c) }\end{array}$ \\
\hline
\end{tabular}

Based on Table 1 and assuming a trailer height of $1.5 \mathrm{~m}$, the maximum allowable length, width and height of a load which can be carried on New Zealand's roads without the need for further permission is $20 \mathrm{~m} \times 2.55 \mathrm{~m} \times 2.8 \mathrm{~m}$. However, there are other considerations such as craning limits for a modular (volume) or factory completed ADU, which could further tighten these limits.

Bringing these results together with the investigation of the location of manufacturers shows currently there are only four manufacturers offering modular prefabricated system breaking down into three in the North and just one in the South Island. Including manufacturers of containers as dwellings increases this number to six factories in the whole country, four in the North and two in the South Island. This suggests a modular approach might not be the best options. However, Figure 7 also shows that the one modular and one container manufacturer in the South Island are both located in the Canterbury region, while in the north, factories are in the three regions of Auckland (2), Waikato (1), and Wellington (1). This tallies with population distribution, as over $50 \%$ of people in the South Island live in Canterbury. As stated earlier, in 2017 Auckland had the biggest population, the highest population density and also the highest population growth rate followed by Waikato and then Wellington and Canterbury respectively. These numbers suggest that using a modular system would be a reasonable starting point for the design, given that the modular approach offers big advantages in terms of time. The long-term solution would be having more manufacturers of modular and complete building, prefabrication dispersed appropriately for the centres of population in both South and North Islands. In Auckland, for example, despite the fact that there are 2 manufacturers of modular prefabrication and 13 of all types (over $25 \%$ of total) there is still a need for more manufacturers there relative to the growing population. For all these reasons it was felt that taking a modular approach to designing a prefabricated ADU was reasonable.

\section{Council rules}

To understand what characteristics a prefabricated ADU should have to get the approval of appropriate councils, the rules of 71 New Zealand councils related to ADUs were investigated in detail. However, 15 councils were first removed from the list, as 13 had no rules regarding ADUs and 2 do not allow the use of cooking facilities in the secondary dwelling. Of the 56 remaining councils and out of the 180 subcategories, only results relating to Maximum Allowable Site Coverage (MASC), Maximum Allowable Gross Plan area (MAGP) and Minimum Net Area (MNA) the site must have in order to be suitable for an ADU, are given in Table 2. The council rules vary considerably, for example, the MASC fluctuates from $10 \%$ to $85 \%$. The MAGP fluctuation rate is lower at $50 \mathrm{~m}^{2}$ $80 \mathrm{~m}^{2}$, while the range for MNA is again great at $200 \mathrm{~m}^{2}$ $1,750 \mathrm{~m}^{2}$. Table 2 summarizes the most commonly occurring rules for ADUs in residential zones from 56 councils.

\begin{tabular}{llll}
\hline $\begin{array}{l}\text { Type of } \\
\text { limitation }\end{array}$ & $\begin{array}{l}\text { Number of } \\
\text { councils }\end{array}$ & $\begin{array}{l}\text { Most common } \\
\text { range }\end{array}$ & $\begin{array}{l}\text { Percentage of } \\
\text { councils } \\
\text { accepting the } \\
\text { range }\end{array}$ \\
\hline MASC & 24 & $30 \%-50 \%$ & $76 \%$ \\
MAGP & 23 & $50 \mathrm{~m}^{2}-70 \mathrm{~m}^{2}$ & $82 \%$ \\
MNA & 21 & $325 \mathrm{~m}^{2-} 800 \mathrm{~m}^{2}$ & $62 \%$ \\
\hline
\end{tabular}

Table 2 shows that for an ADU to be successfully granted permission by the majority of the 56 New Zealand councils it would need to be located on a lot bigger than $325 \mathrm{~m}^{2}$ with a

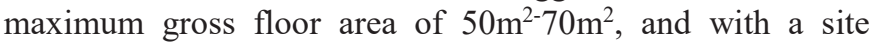
coverage of less than $30 \%$.

When it comes to designing an ADU only the permitted floor area can be a design parameter. The range of $50 \mathrm{~m}^{2}-70 \mathrm{~m}^{2}$ made it difficult to decide on an ideal floor area. As a result another approach was taken. Given the demographic changes and the increase in the sector of the population aged $65+$ a comparison was made with purpose designed units in retirement villages. A typical unit designed for independent living would have a floor are of approximately $50 \mathrm{~m}^{2}-70 \mathrm{~m}^{2}$ and would be single storey (Khajehzadeh and Vale, 2017b). This gave the target floor area for the ADU as it matched that of Table 2. Because the ADU was to be designed to meet the needs of older people this introduced another design parameter. It was decided the ADU should be designed to achieve at least three Lifemark stars. Lifemark is the New Zealand standard that ensures houses are designed to accommodate older people and those with disabilities (Lifemark, 2016).

\section{Design approach:}

Some decision about the type of prefabrication also needs to be made. Although currently, only four manufacturers make modular buildings this was the preferred approach because it reduces time and work on site. Given that the proposal is to site the new ADU on the often large New Zealand sections (plots) craning in modules would reduce the local disruption in terms of noise and added parking from having builders around. A hybrid system, probably using service modules, was 
considered but this would need more on-site work, so it was decided to start the design using the modular approach.

The size of the modules was the next factor. The aim was to achieve the maximum possible flexibility in design, so the ADU could be used by different groups of people, from older people looking for a suitable place to age in their neighbourhood to younger people looking for their first house accommodation. The height and width of modules were the maximum allowed lengths on New Zealand roads, these being respectively $2.8 \mathrm{~m}$ and $2.55 \mathrm{~m}$. The length of the modules was set at $5.1 \mathrm{~m}$, which is twice the module width. This coordination makes the construction process easier and gives the designer more flexibility as modules can be placed together either side by side or head to side (Figure 8 ).

Figure 8 Flexibility of module placement
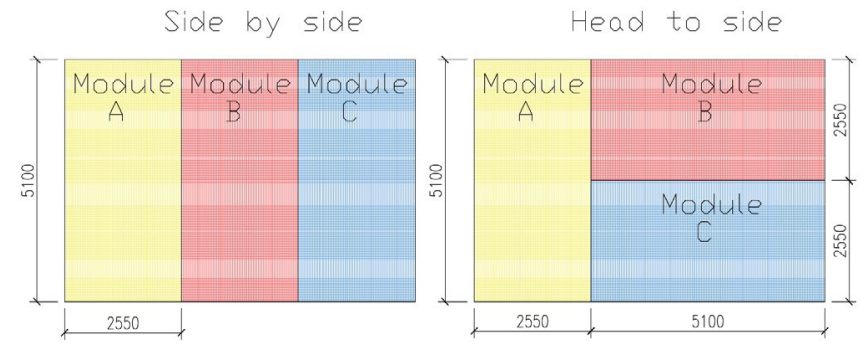

To achieve an open plan for easy internal mobility and sense of space in a small dwelling not all modules could have four walls. This means that some temporary bracing will be required during transportation. The modules are made using Structural Insulated Panels (SIPs), but a full description of the construction details is outside the scope of this paper.

The services and limitations of each modular manufacturer (figure 7) was investigated at this stage to see if they are able to build the ADU. These manufacturers offer different levels of flexibility based on their pre-developed systems. Some like Matrix Homes have pre-developed modules ranging in in size from $52.8 \mathrm{~m}^{2}-138.2 \mathrm{~m}^{2}$ and work with the client to personalise each, or to combine modules together (Matrix Homes, 2018). Others, like Tallwood, work with clients from scratch but ask them to consider all dimensions to be multiples of $600 \mathrm{~mm}$ to reduce the waste, as this is the common dimension for the majority of materials, (Tallwood, 2018). However, this investigation was not helpful to the design of the ADU.

The last factor to be considered was the function of each module. It was decided to give each module only one specific function to make the manufacturing process easier. For example, putting all spaces using water in one module, makes waterproofing simpler and putting all plumbing in one module would minimize the length of pipes. Based on this approach there is a need for at least one module for each bedroom, living room, kitchen and bathroom. However, considering the space needs of each function the kitchen and bathroom were combined into one serviced module. It was decided to have a transition space between inside and outside to minimize heat transfer. As a result, an entrance module was designed to occupy one-third of a standard module.

\subsection{Designs}

Putting all needs and limitations together resulted in the design of over 20 different layouts. All layouts were initially made of four different functional modules (a service module of kitchen and bathroom, bedroom, living area, and entrance), which could be combined in different ways. This approach makes the ADU more flexible so it will be able to fit on different shapes of existing plots, and also respond to the needs of the occupants. Figure 9 shows the functional module sizes and four example layouts to show the flexibility of the approach.

Figure 9 Functional modules and layout examples
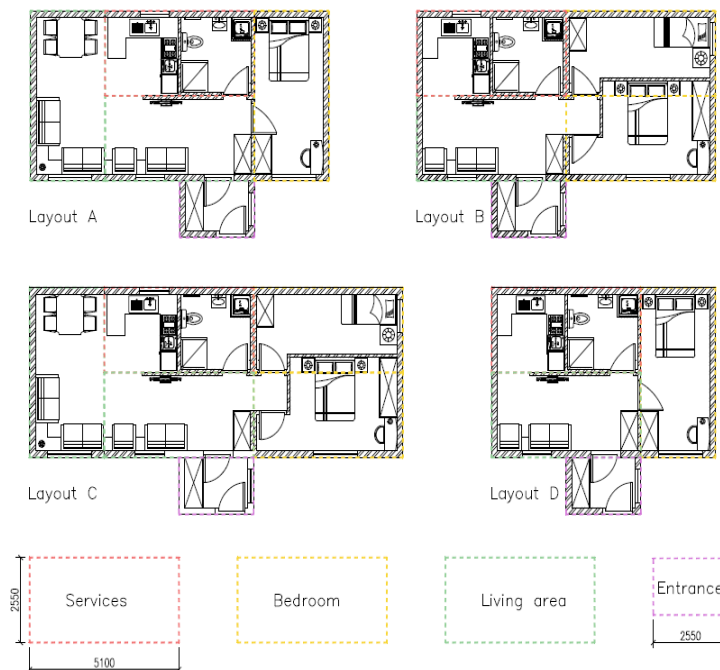

Bedroom
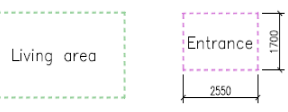

Figure 9 illustrates four example layouts, with layout D being the smallest and layout $\mathrm{C}$ the biggest at respectively $43 \mathrm{~m}^{2}$ and $69 \mathrm{~m}^{2}$. The area of layouts $A$ and B is $56 \mathrm{~m}^{2}$, while layout A has one bedroom rather than two and twice the living area of layout B. With an area of $65 \mathrm{~m}^{2}$ without the entrance module, Table 2 suggests that layout $\mathrm{C}$ would be accepted by 11 councils and by 8 with the entrance module added, whereas layouts $\mathrm{A}$ and $\mathrm{B}$ would be accepted by 23 . However, there is no reason to suggest that these rules might not be reconsidered if prefabricated ADUs were seen as a useful solution to the current housing problems.

\section{Discussion}

The design examples (Figure 9) show that creating prefabricated ADUs as a solution to the housing crisis is feasible. However, there are a number of limitations which need to be considered during the design, transport and assembly stages. The first factor is the availability of prefabrication manufacturers in the region where the ADU is going to be built. Prefabrication has been valued over traditional construction methods due to its efficiency in energy use and time, and its higher quality and potential to be more environmentally friendly and cheaper (Moradibistouni et al, $2018 b)$. However, if there is no factory close to the final 
location of the ADU, the modules need to travel long distances, which can affect the final environmental impact and cost, and this needs to be calculated using a life-cycle energy, emissions, and cost approach. The other point that comes out of travelling long distances is time. Prefabrication can halve the on-site construction time, but this excludes transportation, so this also needs to be factored in. Finally, staying on the roads for a long time potentially increases the chance of damage to modules and especially the joints. This will need to be considered in how the modules are constructed. The siting of new factories for making prefabricated ADUs has, therefore, to be considered carefully.

The next group of considerations is related to the regulation of the building and use of ADUs in New Zealand. Despite the rich history of ADUs, even with different names such as granny flats, there are as yet no comprehensive rules and guidelines regarding building and using them in New Zealand. As a result, each council has its own rules. The differences in ADU related rules could relate to local differences in urban density and housing shortages. However, when it comes to using prefabrication, having a varied set of requirements could be an obstacle, especially for higher degrees of prefabrication such as modular design. Prefabrication is at its most efficient when the design is based on producing a single product for use in different situations. The designs in this paper have set out to show there is still some flexibility even within the current rules, though having a nationwide agreement on rules for ADUs would be the ideal. Given the different needs and limitations in the different regions might mean dividing the country up into centres of the population each with their own rules and their own local factory. However, this will first require acceptance of the idea of prefabricated ADUs.

\section{Summary and conclusion}

The population of New Zealand is following the world trend by growing, with the number of those aged $65+$ also growing. Recent studies have also shown that the size of houses is getting bigger while the size of households is getting smaller, which means a smaller number of people are living in bigger houses. In New Zealand, all these changes have led to a shortage both of houses and smaller houses suitable for accommodating an older population in familiar surroundings. As a consequence, this paper has discussed the practicality of using prefabricated ADUs to build efficient and liveable houses quickly. Prefabrication was selected as a construction method that is potentially faster than traditional methods, while also using sources of energy and materials more efficiently. The aim then became to find a way of prefabricating an ADU so as to provide more houses using existing infrastructure, and also increasing the chances of ageing in place with the least construction related environmental impacts.

Investigating this idea showed there are limitations when it comes to making a prefabricated ADU. Some of the important limitations are the distance between the factory and the final location and how best to bridge this gap. The aim then became to design modules which could be carried on the roads without the need for extra permissions, as these could put economic and time pressures on the project. The other consideration is the different ADU related rules across New Zealand, which should be considered at the design stage.

Despite these limitations, a design was achieved that gave some flexibility, and that could be factory built and craned into place to minimize disruption at the site. However, there is a need for further research into how to achieve a better spread of manufacturers of all types of prefabrication system that would be in balance with the population of each region in both the North and South Islands. There also need for more centralized and uniform rules for ADUs as these would ease both design and manufacturing parameters.

\section{References}

Bell P (2012) Prefab + Green: past, present and future. Prefab NZ, Wellington, New Zealand.

Boulder (2019) Accessory Dwelling Units (ADUs) https://bouldercolorado.gov/housing/adu (accessed 12/01/2019).

Britto J et al. (2008) The business plan for green modular housing. Master's thesis, Donald Bren School of Environmental Science \& Management, Santa Barbara, USA.

Environment Canterbury Regional Council (2018) How many people live in Canterbury? https:/www.ecan.govt.nz/yourregion/living-here/regional leadership/population/censusestimates/ (accessed 23/11/2018).

Evans B (2012) Goodbye urban sprawl, hello apartments. Build. June-July 2012, BRANZ, Wellington, New Zealand.

Gorgolewski M T (2005) The Potential for Prefabrication in United Kingdom Housing to Improve Sustainability. Yang et al (eds) Smart \& Sustainable Built Environments. Blackwell, Oxford, UK, pp. 119-128.

Khajehzadeh I and Vale B (2017a) How house size impacts type, combination and size of rooms: a floor plan study of New Zealand houses. Architectural Engineering and Design Management 13(4): 291-307.

Khajehzadeh I and Vale B (2017b) Estimating the Floor Area of a House Knowing its Number of Rooms and how these are named. Proceedings of the Back to the Future: The Next 50 Years, (51st International Conference of the Architectural Science Association (ANZAScA)) (Schnabel M A) Wellington, New Zealand, pp. 315-323.

Khawaja M and Thomson N (2000) Population ageing in New Zealand. Key statistic, Statistics New Zealand, Wellington, New Zealand.

Lifemark (2016) Design standards handbook New Zealand, Lifemark design Ltd, Aukland, New Zealand.

Matrix Homes (2018) Home making: How to buy a Matrix. https://www.matrixhomes.co.nz/process (accessed $12 / 05 / 2018)$

Miller C (2017) MBIE figures show nationwide housing shortage

of 71,000 
https://www.nzherald.co.nz/business/news/article.cfm?c_id=3 \&objectid=11940328 (accessed 12/10/2018).

Mimoso M (2019) Two Houses Make a Home https://www.behance.net/gallery/55344823/Two-HousesMake-a-Home-Interior-Design-Project (accessed 12/02/2019).

Moradibistouni M and Gjerde M (2017) Potential for Prefabrication to Enhance the New Zealand Construction Industry. Proceedings of the Back to the Future: The Next 50 Years, (51st International Conference of the Architectural Science Association (ANZAScA)) (Schnabel M A) Wellington, New Zealand, pp. 427-435.

Moradibistouni M et al. (2018a) The potential role of prefabrication in the New Zealand housing crisis: a study of manufacturers of prefabrication in New Zealand. Proceedings of the Engaging Architectural Science: Meeting the Challenges of Higher Density: 52nd International Conference of the Architectural Science Association. (Rajagopalan P) Melbourne, Australia, pp. 137-144.

Moradibistouni M et al. (2018b) Learning from the past to build tomorrow: an overview of previous prefabrication schemes. Proceedings of the Engaging Architectural Science: Meeting the Challenges of Higher Density: 52nd International Conference of the Architectural Science Association. (Rajagopalan P) Melbourne, Australia, pp.145-152.

New Zealand Transport Agency (2017a) Heavy rigid vehicles. Factsheet13a. New Zealand Transport Agency, Wellington, New Zealand.

New Zealand Transport Agency (2017b) Heavy trailers and combination vehicles (full, semi, simple, pole, A- and B-train). Factsheet13c. New Zealand Transport Agency, Wellington, New Zealand.

New Zealand Transport Agency (2017c) Vehicle dimensions and mass guide to factsheet 13 series. Factsheet13. New Zealand Transport Agency, Wellington, New Zealand.

Petterson J (2016) Review of the Land Transport Rule: Vehicle Dimensions \& Mass 2002 Regulatory Impact Statement New Zealand, New Zealand Government.

Phillipson M (2001) New and Improved Technologies and Techniques Defining the Sustainability of Prefabrication and Modular Process in Construction. BRE Scotland and Dept. of Trade and Industry, Glasgow, Scotland.

Quotable Value (QV) (2011) Average house size by age. https://www.qv.co.nz/property-insights-blog/average-housesize-by-age/62 (accessed 10/04/2018).

Road transport forum NZ (2018) New Zealand's Truck Fleet. https://www.rtfnz.co.nz/new-zealand-road-transport/newzealands-truck-fleet/ (accessed 12/11/2018).

Saville-Smith K et al. (2017) ADU potential: have we the potential to use our existing stock of homes to create a bigger stock of affordable, fit for purpose homes? Building Better Homes. New Zealand, Centre for Research, Evaluation and Social Assessment (CRESA), Wellington, New Zealand.

Statistics New Zealand (2014) 2013 Census, QuickStats about families and households. http://archive.stats.govt.nz/Census/2013-census/profile-and- summary-reports/qstats-families-households/households.aspx (accessed 09/10/2018).

Statistics New Zealand (2015) Subnational family and household projections: 2013(base)-2038 https:/www.stats.govt.nz/information-releases/subnationalfamily-and-household-projections-2013base2038 (accessed 01/06/2018).

Statistics New Zealand (2016) National Population Projections: 2016(base)-2068

http://archive.stats.govt.nz/browse_for_stats/population/estim ates_and_projections/NationalPopulationProjections_HOTP2 016.aspx (accessed 01/09/2018).

Statistics New Zealand (2017a) Household income and housing-cost statistics: Year ended June 2017 - corrected. https://www.stats.govt.nz/methods/price-indexes-for-theconstruction-industry (accessed 15/12/2017).

Statistics New Zealand (2017b) Three in four New Zealanders live in the North Island. https://www.stats.govt.nz/news/threein-four-new-zealanders-live-in-the-north-island (accessed $10 / 12 / 2017)$.

Statistics New Zealand (2017c) Population growth fastest in Northland, Auckland, and Waikato. https://www.stats.govt.nz/news/population-growth-fastest-innorthland-auckland-and-waikato (accessed 26/11/2018).

Stockdale M (2016) Review of the Vehicle Dimensions \& Mass Rule, The New Zealand Automobile Association, Auckland, New Zealand.

Tallwood (2018) Designing a Building for manufacture with Tallwood: 7 principles for success. https://tallwood.co.nz (accessed 09/10/2018). 